\title{
Modelling of a Tesla turbine gap between the rotor disks
}

\author{
Andromachi Papagianni ${ }^{1}$, Theofilos Efstathiadis ${ }^{1}$, Aggelos Gaitanis ${ }^{1}$, and Anestis Kalfas $^{1}$ \\ ${ }^{1}$ Aristotle University of Thessaloniki, Greece
}

\section{Introduction}

In the present study, a Tesla turbine is examined, for waste heat recovery applications. It's use concerns mainly the replacement of the lamination valve for the expansion of the fluid. During operation, phase change of the working fluid occurs in the inlet convergent nozzle, from a liquid flow, to a mainly steam flow with liquid droplets. Some of these droplets concentrate in the rotor's surface creating a liquid film between the disk and the working fluid, preventing the flow from being in direct contact with the rotor disks [1], [2]. The main goal of the study is to evaluate the effect of the liquid film formation in a two-phase Tesla turbine [3]. When the liquid film is formed, according to its thickness, the gap size between the rotor discs is reduced. For this reason, a parametric analysis has been made in the gap of the turbine rotors to account for the liquid film. For each of the gap values the output torque is estimated. The analysis results are extracted through a CFD simulation.

\section{Methodology}

Four different disk gap sizes, $1 \mathrm{~mm}, 0.9 \mathrm{~mm}, 0.8 \mathrm{~mm}, 0.7 \mathrm{~mm}$, have been simulated in order to assess their impact on the produced torque. Firstly, an unstructured mesh of approximately 8 million cells was created for the $1 \mathrm{~mm}$ case. This mesh was later altered to account for the smaller disk gap cases. Minimum tip clearance of $0.5 \mathrm{~mm}$ was used between the rotor and the casing. The nozzle and casing geometries remained the same, while starting from the outer radius of the rotor, the disk gap gradually decreased to the desired one. In this preliminary study, the four geometries have been modelled in CFD, in the commercial software ANSYS FLUENT 18.0, with steam as working fluid, since steam phase produces the output torque. The cases were simulated using a pressure-based solver with SIMPLE algorithm for pressure-velocity coupling. The SST k - $\omega$ turbulence model is used to model the turbulence of the flow and the maximum $\mathrm{y}^{+}$is 2.1 . The chosen turbulence model is validated both for external and internal flows and is currently the industry standard for turbulence modelling.

\section{Results}

Figure 1 presents the measured torque of the four different disc gap sizes versus a rotational speed range of $5000-30000 \mathrm{rpm}$. According to the results, until $15000 \mathrm{rpm}$ the output torque is lower as the gap size decreases. However, for higher rotational speed, the $0.7 \mathrm{~mm}$ case has a less steep drop, compared to the $1 \mathrm{~mm}$ case, that leads to the maximum output torque at $30000 \mathrm{rpm}$. The maximum torque of the smallest gap size case can be better understood in the Figure 2, where the radial velocity of the cases is depicted. When the fluid exits the nozzle and enters the rotor a region of positive radial velocity is formed. Ideally, the radial velocity should be negative in the rotor so that the fluid moves towards the outlet. In the 
$0.7 \mathrm{~mm}$ case the radial velocity contour has the smallest positive region, so the fluid's momentum is better extracted and used in the rotor, leading to the highest output torque.

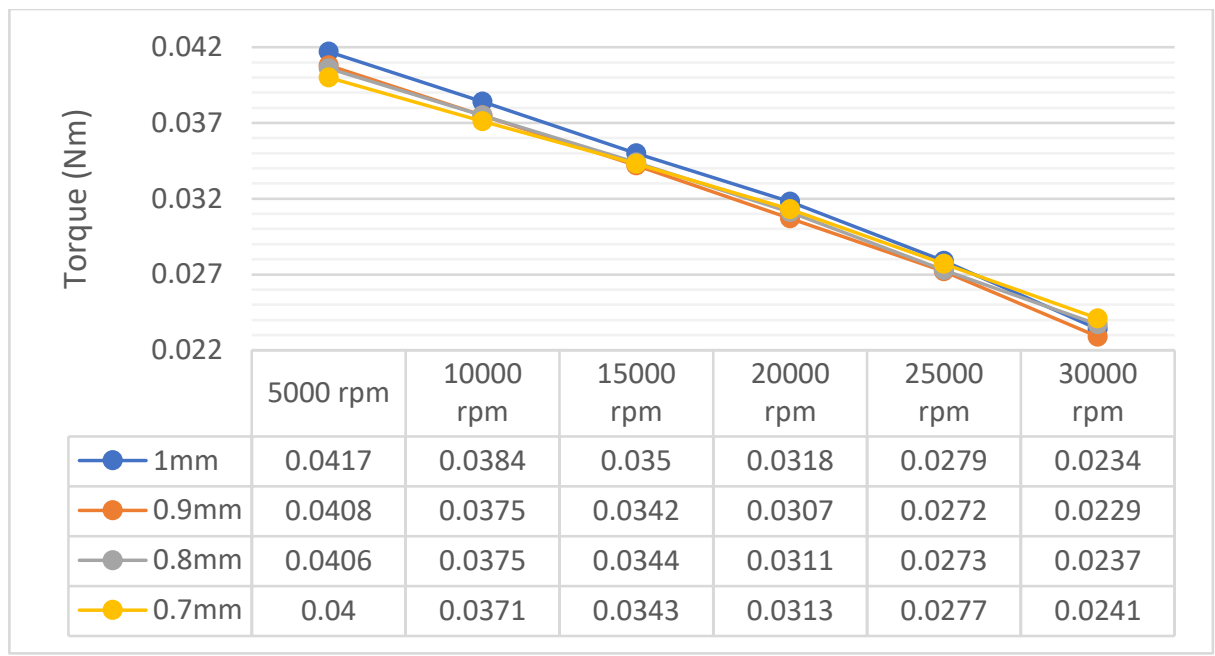

Figure 1. Output torque vs rotational speed for different disc gap sizes $(1,0.9,0.8,0.7 \mathrm{~mm})$
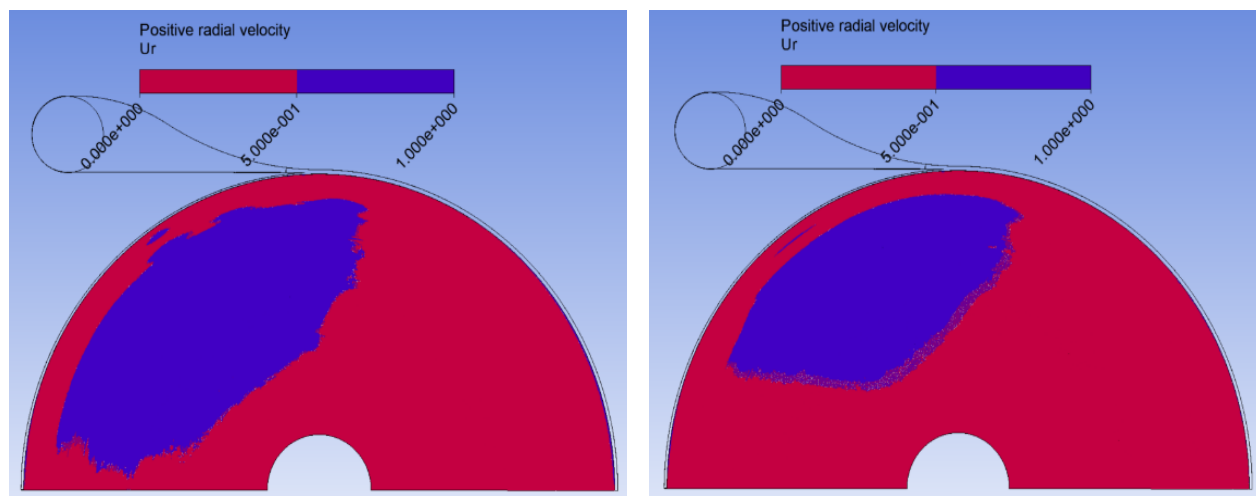

Figure 2: Region of positive radial velocity $(0$ - negative-red, 1- positive-blue) for $1 \mathrm{~mm}$ (left) and $0.7 \mathrm{~mm}$ (right) cases

\section{Conclusions}

Concluding, according to the torques' preliminary results, for low rotational speed, the tighter gap between the rotor disks has a negative effect, whereas for higher rotational speed is beneficial for the output torque. The $0.7 \mathrm{~mm}$ case in particular, features a $3 \%$ increase in the produced torque compared to the $1 \mathrm{~mm}$ case for $30000 \mathrm{rpm}$.

\section{References}

1. T. Nikolaidis, P. Pilidis, J. A. Teixeira, V. Pachidis, Water Film Formation on an Axial Flow Compressor Rotor Blade, ASME Paper No. GT2008-50137, June 9-13, 2008, Berlin, Germany

2. L. Sun, Q. Zheng, M. Luo, Y. Li, R. Bhargava, On the Behaviour of Water Droplets When Moving Onto Blade Surface in a Wet Compression Transonic Compressor, J. Eng. Gas Turb. Power 133(8), (2011)

3. Tesla, N., 1913. Turbine. US, Patent No. 1061206. 